\title{
COMPARISON OF ISO METHOD WITH TWO NEW METHODS FOR DETERMINING THE RADIO-OPACITY OF RESTORATIVE RESINS.
}

\author{
Rishabh Kapila ${ }^{1}$, Yukiko Matsuda ${ }^{2}$, Keiichi Nishikawa ${ }^{3}$, Tsukasa Sano ${ }^{4}$ \\ ${ }^{1,2,4}$ Division of Radiology, Department of Oral Diagnostic Sciences, Showa University School of Dentistry, Tokyo, Japan \\ ${ }^{3}$ Department of Oral \& Maxillofacial Radiology, Tokyo Dental College, Tokyo, Japan
}

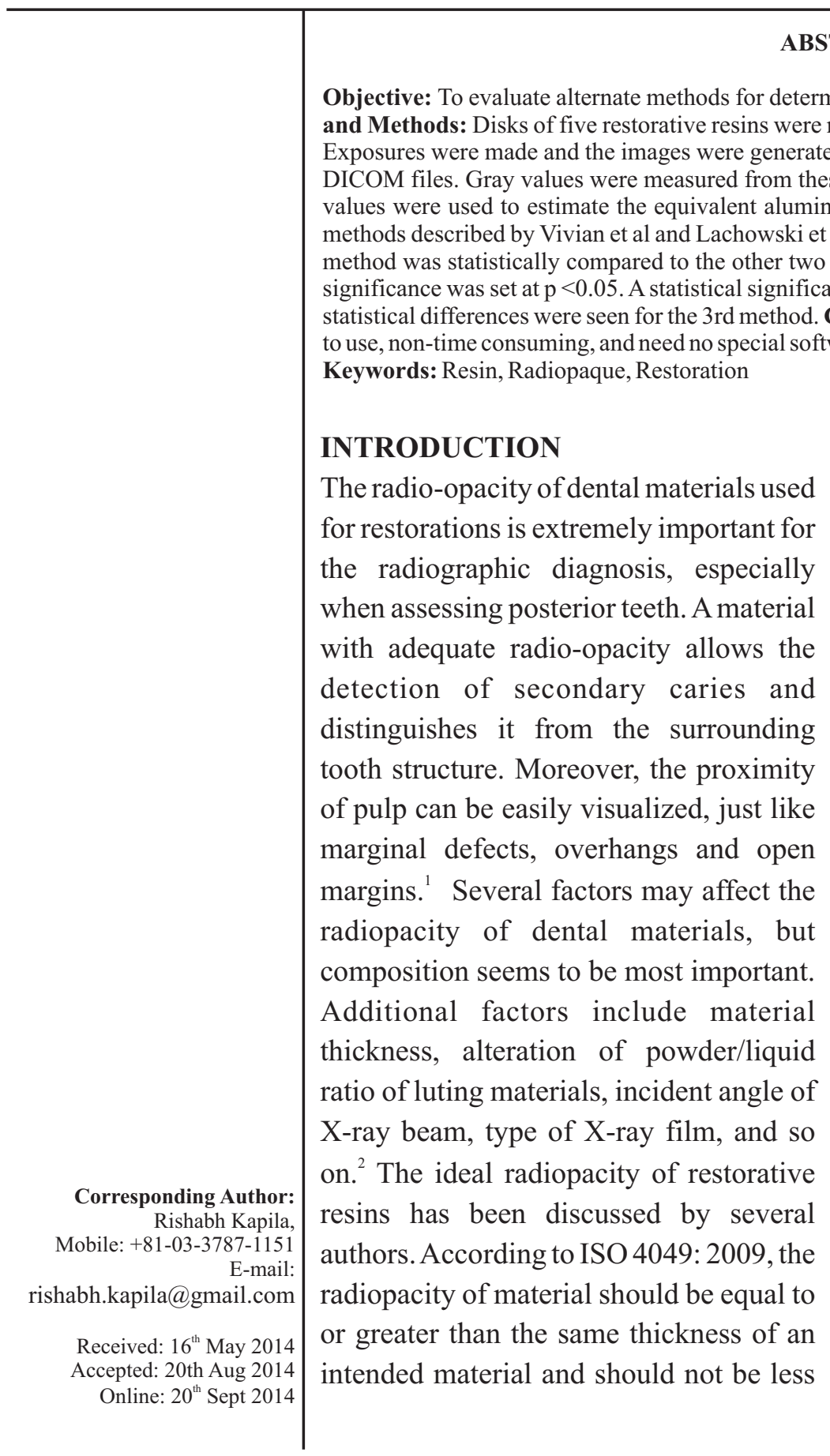

\section{ABSTRACT}

Objective: To evaluate alternate methods for determining the radio-opacity of restorative resins. Materials and Methods: Disks of five restorative resins were made and placed on the sensor of intraoral X-ray sensor. Exposures were made and the images were generated without using automatic gain control and exported as DICOM files. Gray values were measured from these images using Image-J software. Results: These gray values were used to estimate the equivalent aluminium thickness in $\mathrm{mm}$ using the ISO method and using methods described by Vivian et al and Lachowski et al. The equivalent aluminium values obtained from ISO method was statistically compared to the other two methods using ANOVA and Dunnet's test. The level of significance was set at $\mathrm{p}<0.05$. A statistical significant difference was seen for the 2 nd method. However, no statistical differences were seen for the 3 rd method. Conclusion: The alternate methods are relatively simple to use, non-time consuming, and need no special softwares for calculations.

Keywords: Resin, Radiopaque, Restoration

\section{NTRODUCTION}

The radio-opacity of dental materials used for restorations is extremely important for he radiographic diagnosis, especially with adequate radio-opacity allows the detection of secondary caries and distinguishes it from the surrounding ximity of pulp can be easily visualized, just like marginal defects, overhangs and open margins. ${ }^{1}$ Several factors may affect the s, bu composition seems to be most important. Additional factors include material thickness, alteration of powder/liquid ratio of luting materials, incident angle o X-ray beam, type of X-ray film, and so on. ${ }^{2}$ The ideal radiopacity of restorative resins has been discussed by several authors. According to ISO 4049: 2009, the radiopacity of material should be equal to or greater than the same thickness of an intended material and should not be less than $0.5 \mathrm{~mm}$ of any value claimed by the manufacturer. ${ }^{3}$ It has been demonstrated that the radio-opacity of dentine is approximately equivalent to that of $\mathrm{Al}$ with the same thickness, and enamel has approximately twice the radio-opacity of Al with the same thickness. ${ }^{1}$

The digital image analysis has been considered of the same accuracy as transmission densitometry and can be equivalent to film but with less noise, providing precise and trustworthy numerical values and comparative radiodensity studies. In digital image analysis we can measure radiographic density directly, because the pixels already have their determined gray shades, directly providing the values at a scale of 0 to 255 and so on. Also, it is not necessary to perform any subtraction (as done in conventional X-ray films) when calculating the radiopacity. ${ }^{4}$ The use of digitized images and computer-aided 
radiographic image analysis with softwares especially designed for this purpose has allowed the development of radiopacity studies with more simplified and reproducible methodologies that can provide reliable results. ${ }^{5}$ Direct digital image, as produced by RVG, would reduce the loss of information that should occur with the use of indirect digital image or film. ${ }^{6}$ The ISO method has been considered as a gold standard for evaluating the radiopacity of materials. Recently, Vivian et $\mathrm{al}^{7}$ and Lachowski et $\mathrm{al}^{1}$ used two mathematical formulas to calculate the radiopacity of materials by the aluminium equivalent method using digital radiographic methods. These formulas provided simple calculations for estimating the aluminium equivalent, thereby saving time and the more difficult analysis of the ISO method.

Thus, the aim of the study was to calculate and compare the aluminium equivalent obtained by all the three methods, i.e. ISO method and the two formula methods as described by Vivian et al and Lachowski et al using RVG.

\section{MATERIALS AND METHODS}

Preparation of specimens

Each of the five restorative resins was made into $1 \mathrm{~mm}$ thick disks, measured to an accuracy of $\pm 0.01 \mathrm{~mm}$ using a micrometer, according to the guidelines of ISO 4049:2009. An aluminium step wedge was also fabricated with more than $98 \%$ purity and had steps of $1.0,1.5,2.0,3.0,4.0,6.0,8.0$ and $10.0 \mathrm{~mm}$ in thickness. The materials used in the study are given in table 1 .

\section{Exposure conditions}

The specimens along with the aluminium step wedge were placed on the digital intraoral X-ray sensor RVG 5000 (Kodak, Rochester, NY, USA). The sensor was

Table 1: Light cure composite resin materials

\begin{tabular}{|l|l|}
\hline Material & Manufacturer \\
\hline Sorare ${ }^{\circledR}$ P & GC Dental (Tokyo, Japan) \\
\hline Gradia ${ }^{\circledR}$ DirectX & GC Dental (Tokyo, Japan) \\
\hline Estelite ${ }^{\circledR}$ Sigma Quick & Tokuyama Dental Corp. \\
\hline Clearfil@ AP-X & Kuraray Medical Inc. (Tokyo, Japan) \\
\hline Beautiful@ II & Shofu Inc. (Kyoto, Japan) \\
\hline
\end{tabular}

fixed to hold it parallel to the horizontal plane to allow radiography in the perpendicular direction to the horizontal plane and to reduce the radiation intensity variation in the central $\mathrm{x}$-ray beam due to the anode heel effect. The X-ray unit was kept in the same position throughout the experiment. The X-ray unit used in this study was an inverter-type Max-DC 70 (J Morita, Kyoto, Japan) with tube voltage of $65 \mathrm{kV}$, tube current of $10 \mathrm{~mA}$, and total filtration of $2.5 \mathrm{~mm}-\mathrm{Al}$ equivalent. Exposure time and focus-to-sensor distance were fixed at $0.05 \mathrm{~s}$ and $30 \mathrm{~cm}$, respectively. Each of the resin was radiographed five times and a direct digital image was displayed onto the computer display.

\section{Image analysis}

The images were generated without using automatic gain control and were exported as DICOM files. The files were read with an ImageJ software (ver. 1.46; $\mathrm{NIH}$, Bethesda, MD, USA) and gray values were measured (Figure 1). A region of interest (ROI) with $50 \times 50$ pixels was set at each step of the step wedge and the resin disk, avoiding any voids and cracks. Measurements were repeated 5 times. Total of 25 gray values ( 5 images $\mathrm{x} 5$ measurements) were used for calculating mean gray values (MGVs).

Aluminium equivalent thickness

Aluminium equivalent values of each resin were calculated based on three methods:

a) ISO method

A mean value graph was generated using the Excel spreadsheet (Ver. 2007). In the graph the Y- axis denotes the thickness of aluminium step in $\mathrm{mm}$ and $\mathrm{X}$ axis denotes the corresponding mean gray value of the step. A regression equation was obtained from each graph using the third degree polynomial equation up to 10 decimal places. The reliability of each regression equation ( $\mathrm{R} 2$ value; $\mathrm{R}$ is a correlation coefficient) exceeded 0.99. According to ISO recommendations, the slope of the graph may be used only when the correlation coefficient of the plot, is more than 0.97. This equation was used to calculate the aluminium equivalent thickness of the resins, in mm (Figure 2). 
b) Method described by Vivian et al

Vivian et al derived a formula for evaluation of radioopacity of root end filling materials, which has also been used by Marco. The formula is as follows:

Aluminium equivalent thickness $(\mathrm{mm}-\mathrm{Al})=$

$$
\frac{\mathrm{A} \times 2}{\mathrm{~B}}+\underset{\text { material }}{\text { mm-Al immediately below gray value of }}
$$

Where, $\mathrm{A}=$ gray value of material - gray value of aluminium step immediately below the gray value of material, $\mathrm{B}=$ gray value of aluminium step immediately above the gray value of material - gray value of aluminium step immediately below the gray value of material We compared the aluminium equivalent thicknesses obtained using this simple formula with the ISO method.

c) Method by Lachowski et al (modified Vivian's formula)

Lachowski et al modified the formula initially given by Vivian et al., which is as follows:

Aluminium equivalent thickness $(\mathrm{mm}-\mathrm{Al})=$

$\frac{\mathrm{A}-\mathrm{B}}{\mathrm{C}-\mathrm{B}} \times$ sample thickness + mm-Al immediately

Where, $A=$ gray value of material below gray value of material

$\mathrm{B}=$ gray value of aluminium step immediately below the gray value of material

$\mathrm{C}=$ gray value of aluminium step immediately above the Gray value of material.

We also compared the aluminium equivalent thicknesses obtained using this simple formula with the ISO method.

\section{STATISTICALANALYSIS}

The statistical calculations were carried out using a Statistical Package for Social Sciences (SPSS) for Windows 17.0 software (SPSS Inc., Chicago, IL, USA). Data were analysed using analysis of variance (ANOVA). Then, the Dunnets test was used to make multiple comparisons. The level of significance was set at $\mathrm{p}<0.05$.

\section{RESULTS}

The mean aluminium equivalent thicknesses obtained for all the five resins by the three methods are shown in Table 2. The results showed that all resins have more than $1 \mathrm{~mm}$ of aluminium equivalent thickness, as has been outlined in ISO 4049: 2009. Among the five resins, Sorare had the mininal radiopacity, while Clearfil had the maximal radiopacity. Since the ISO method is considered to be the gold standard for determination of aluminium equivalent thickness the other two methods were compared to the ISO method using ANOVA and Dunnet's test. A statistical significant difference was seen for the 2 nd method. However, no statistical differences were seen for the 3rd method (Table 3 and Figure 3).

\section{DISCUSSION}

Since olden days, human beings have searched for restoration of esthetics and masticatory function. In order to meet these requirements satisfactorily, metal alloys, silver amalgam and resins were employed. Buonocore suggested the utilization of acids to alter the tooth surface and make resins more suitable. ${ }^{8}$ In 1979 the Standard Association of Australia required the restorative materials of composite resin to have a high radiopacity. ${ }^{8}$ The American Dental Association included the radiopacity in the specifications for dental materials in 1981. Thus, it was established that dental materials should have the same or greater radiopacity compared to radiolucent areas suggesting caries. ${ }^{8}$ In order to evaluate the radiopacity, Cook recommended that aluminium is the material of choice, because it presents the same linear coefficient of absorption as enamel. ${ }^{8}$ The material's composition

Table 2: The mean aluminium equivalent thicknesses (S.D.) in mm by 3 methods.

\begin{tabular}{|l|l|l|l|}
\hline Material & ISO method & 2nd Method & 3rd Method \\
\hline Sorare & $1.66(0.05)$ & $2.22(0.23)$ & $1.85(0.11)$ \\
\hline Gradia & $2.49(0.02)$ & $2.92(0.05)$ & $2.46(0.03)$ \\
\hline Estelite & $2.21(0.005)$ & $2.44(0.01)$ & $2.24(0.01)$ \\
\hline Clearfil & $3.76(0.08)$ & $4.42(0.23)$ & $3.70(0.13)$ \\
\hline Beautiful & $3.72(0.05)$ & $4.36(0.12)$ & $3.68(0.06)$ \\
\hline
\end{tabular}


Table 3: Multiple comparisons between the 2nd method and ISO method, and between the 3rd method and the ISO method.

Dunnett t (2-sided)

\begin{tabular}{|c|c|c|c|c|c|c|c|}
\hline \multirow{2}{*}{$\begin{array}{l}\text { Dependent } \\
\text { Variable }\end{array}$} & \multirow{2}{*}{ (I) Type } & \multirow{2}{*}{ (J) Type } & \multirow{2}{*}{$\begin{array}{c}\text { Mean } \\
\text { Difference (I-J) }\end{array}$} & \multirow{2}{*}{ Std. Error } & \multirow[b]{2}{*}{$\mathrm{p}$-value } & \multicolumn{2}{|c|}{$95 \%$ Confidence Interval } \\
\hline & & & & & & Lower Bound & Upper Bound \\
\hline \multirow[t]{2}{*}{ Sorare } & 2nd method & ISO method & .55800 & .09677 & $.000 *$ & .3158 & .8002 \\
\hline & 3rd method & ISO method & .19600 & .09677 & .115 & -.0462 & .4382 \\
\hline \multirow[t]{2}{*}{ Gradia } & 2nd method & ISO method & .43200 & .02543 & $.000 *$ & .3684 & .4956 \\
\hline & 3rd method & ISO method & -.03200 & .02543 & .375 & -.0956 & .0316 \\
\hline \multirow[t]{2}{*}{ Estelite } & 2nd method & ISO method & .24200 & .01536 & $.000 *$ & .2036 & .2804 \\
\hline & 3rd method & ISO method & .03600 & .01536 & .066 & -.0024 & .0744 \\
\hline \multirow[t]{2}{*}{ Clearfil } & 2nd method & ISO method & .65600 & .10352 & $.000^{*}$ & .3969 & .9151 \\
\hline & 3rd method & ISO method & -.06400 & .10352 & .766 & -.3231 & .1951 \\
\hline \multirow[t]{2}{*}{ Beautiful } & 2nd method & ISO method & .64600 & .05564 & $.000^{*}$ & .5068 & .7852 \\
\hline & 3rd method & ISO method & -.03800 & .05564 & .725 & -.1772 & .1012 \\
\hline
\end{tabular}

*. The significant difference was seen $(\mathrm{p}<0.05)$.

seems to be the most important factor that influences radio-opacity. The manufacturers include chemical elements such as barium, zinc, aluminium, strontium, silicon, yttrium, ytterbium and lanthanum in the products to increase radio-opacity. The higher the atomic number of the element added to the radioopaque filler of the material composition, the higher the radio-opacity of the materials, because the absorption capacity of X-rays is increased. Therefore, ytterbium, which has the atomic number 70 , is the element that provides the highest radio-opacity, followed by barium $(Z=56)$, yttrium $(Z=39)$, strontium $(Z=38)$, zinc $(Z=$ $30)$, silicon $(Z=14)$ and aluminium $(Z=13)$.

Digital imaging systems have been used in dental practice, providing advantages over conventional radiographic films, such as involving a shorter exposure time of X-rays, faster and easier generations of X-ray images, and accurate evaluation of radio- opacity. These advantages can also be employed in laboratory research to evaluate the radio-opacity of dental materials. With this system, the radiograph is available for computer image software to determine the mean gray values (MGVs) of each material or structure, which are represented within a scale ranging between 0 (black) and 255 (white) and so on. ${ }^{1}$

Eliasson and Haaske $^{6}$ established a comparison standard for radiopacity studies using optical density values and calculating the equivalent in millimeters of aluminium that results in similar values of radiographic density. Tagger and $\mathrm{Katz}^{6}$ developed a method for measuring radiopacity by obtaining radiographic images of the material alongside an aluminium stepwedge (penetrometer). This method involves digitalization of the radiographic images and the use of specific software to detect the different gray-scale values. ${ }^{6}$ 


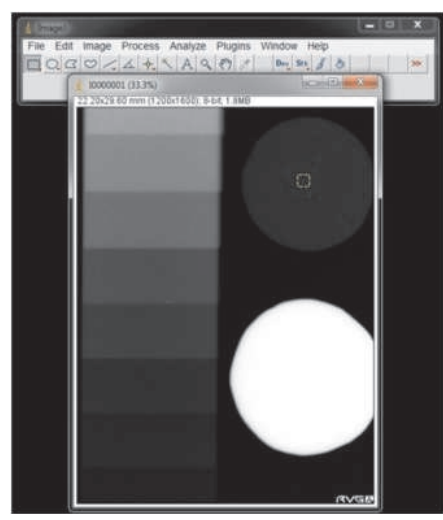

Figure 1: Gray value measurement using a 50 x 50-pixel ROI. ROI was set at each step and the resin disk.

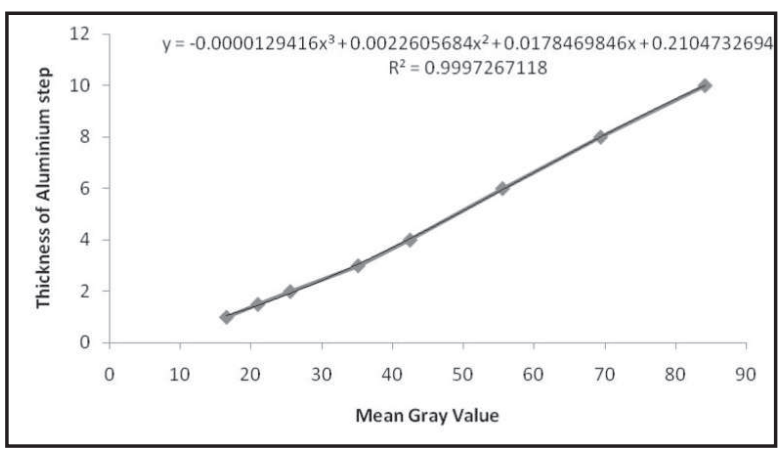

Figure 2: A sample of the obtained graphs with a polynomial equation used to obtain the equivalent aluminium equivalent thickness in $\mathrm{mm}$.

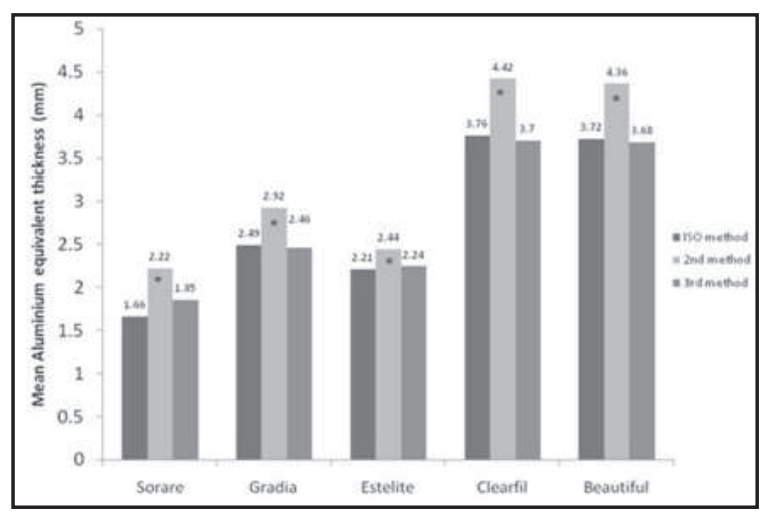

Figure 3: Bar graph for comparisons of mean aluminium equivalent thicknesses obtained by the three methods. The bars with * showed the significant differences $(p<0.05)$ for the ISO method.
The ISO method has been widely recognised and followed for evaluation of the radiopacity of materials. In the present study we compared the ISO method with two different methods based on simple calculations, which do not require the creation of graphs and solving of the tedious polynomial equations. The materials that were investigated in the present study satisfied the specifications outlined by ISO 4049, whereas they showed large variation in radio-opacity. The aluminium equivalent thicknesses obtained by the formula derived from Vivian et $\mathrm{al}^{7}$ (2nd method) showed significant differences from the ISO method, while no difference was seen for the formula derived from Lachowski et al ${ }^{1}$ (3rd method).

Differences in the results might be due to different methodology. Vivian et $\mathrm{al}^{7}$ (2nd method) digitised the conventional occlusal radiographs with a Nikon D40 camera. Moreover, they used a stepwedge with increments of $2 \mathrm{~mm}$ thickness. On the other hand, the formula used by Lachowski et $\mathrm{al}^{1}$ (3rd method), which was more precise, took into account the sample thickness and used an aluminium stepwedge with unequal increments of thickness. The similar result between ISO method and 3rd method might be due to the use of same digital sensor (RVG 5000).

\section{CONCLUSION}

More studies focussing on the effects of difference in imaging systems and exposure parameters should be carried out. The present study used a polynomial equation in the ISO method for the evaluation of radiopacity of restorative resins. The alternate formula based methods are relatively simple to use, non-time consuming, and need no special softwares for calculations. However, further studies are still required to confirm the above findings.

\section{REFERENCES}

1. Lachowski K M, Botta S B, Lascala CA, Matos A B, Sobral M A P. Study of the radio-opacity of base and liner dental materials using a digital radiography system. Dentomaxillofacial Radiology 2013; 42: 20120153. 
2. Altitas S H, Yildirim T, Kayipmaz S, Usumez A. Evaluation of radiopacity of luting cements by digital radiography. Journal of Prosthodontics 2013;22 (4): 282-286.

3. Dentistry-polymer-based restorative materials, ISO 4049. 4th ed; Geneva: International Organization for Standardization; 2009.

4. Dukic W, Delija B, Derossi D, Dadic I. Radiopacity of composite dental materials using a digital X-ray system. Dental Materials Journal 2012;31(1): 47-53.

5. Húngaro Duarte M A, de Oliveira El Kadre G D, Vivan R R, Guerreiro Tanomaru J M, Tanomaru Filho M, de Moraes I G. Radiopacity of Portland cement Associated With Different Radiopacifying Agents. J Endod 2009; 35 (5):737-740.
6. Salzedas L M, Louzada M J, de Oliveira Filho A B. Radiopacity of restorative materials using Digital images. J Appl Oral Sci. 2006;14 (2):147-52

7. Vivan R R, Ordinola-Zapata R, Bramante C M, Bernardineli N, Garcia R B, Hungaro Duarte M A, de Moraes I G. Evaluation of the radiopacity of some commercial and experimental root-end filling materials. Oral Surg Oral Med Oral Pathol Oral Radiol Endod 2009; 108 (6):e35-e38.

8. Castilho J C, Takeshita W M, dos Santos L R, de Moraes L C, Medici Filho E, de Moraes M E. Digital Radiographic Evaluation of Optical Density of Porcelains Used For Fabrication of Inlay/Onlay Prosthesis. J Appl Oral Sci. 2006; 14(1):16-20. 